\title{
Diálogo e controvérsia na modernidade pré-crítica: o caso Descartes
}

\author{
Maria Luisa Ribeiro Ferreira \\ "No man is an Iland, intire of itselfe; every man \\ is a peece of the Continent, a part of the maine" \\ John Donne
}

\section{O preconceito do filósofo autista}

A imagem mais divulgada do filósofo moderno, vê-o como uma espécie de eremita, um indivíduo isolado que solitariamente constrói o seu sistema, afastado dos outros, mesmo quando esses outros são filósofos. Talvez que esta interpretação se justifique por uma característica comum a todo o pensador moderno - o desejo de se colocar como pai fundador de um modo "novo" de pensar, ignorando quer aqueles que o precederam, mergulhadores das mesmas águas, quer os seus contemporâneos, com os quais partilha inquietações e certezas.

Note-se que este autismo filosófico é mais forjado do que real. Embora avaros no que respeita a citações, os pensadores modernos conhecem bem a tradição filosófica e estão a par do que pensa a "intelligentsia" do seu tempo. Na sua cela de frade, Marin Mersenne faz cruzar redes de informação científica e filosófica que o colocam no coração da modernidade. Na solidão de um quarto sobreaquecido, Descartes responde às objecções dos seus pares. No exílio a que o "herem" o condenou, Espinosa tem acesso à última palavra no que respeita às ciências ópticas e à química.

As universidades perdem a exclusividade no controlo dos saberes. Estes processam-se à margem da instituição escolar, organizam-se em pequenos círculos e privilegiam as relaçỗes face a face. O filósofo seiscentista abandona a Universidade, passando a preceptor ou a investigador. O espírito comunitário restringe-se a pequenos grupos de discípulos que se reclamam de um mestre cuja grandeza de espírito admiram. Contudo, há uma distância abissal entre o autor consagrado e os seus seguidores, os quais, exceptuando os cartesianos, raramente formam escola. Só que o isolamento é aparente. Os grandes filósofos conhecem-se entre si, lêem-se e discutem. Se por vezes explicitamente se criticam, outras há em que aproveitam teses uns dos outros, para depois seguirem, cada um, o seu caminho original. Assim, a modernidade é perpassada por uma alternância de controvérsia e de diálogo, o que contraria a ideia do filósofo autista, isolado do mundo e dos outros, desenvolvendo as suas teses numa torre de marfim. 
No dizer de Susanne Langer, há "ideias geradoras" (generative ideas) que enformam as mundividências filosóficas dominantes ${ }^{1}$. São elas que constituem a língua que os intelectuais falam e os conceitos que privilegiam, sem necessidade de os apresentar ou justificar. Também a modernidade utiliza uma mesma linguagem, com as suas idiossincrasias e tiques, os seus temas de eleição, os seus amores e ódios. Mas para além desse caldo comum que a todos enforma (ou deforma) há divergências fundas, discordâncias que manifestamente se afirmam, posições irredutíveis que se consolidam no esgrimir de argumentos e contra-argumentos. Tais diferenças concretizam-se por escrito, em textos maiores mas também em ensaios, em cartas, por vezes em meras notas de rodapé. É o seu registo que marca o ritmo do pensamento e nos dá o pulsar de uma época. É esse confronto de posições e de teses que humaniza os filósofos, mostrando a fragilidade dos seus argumentos, as suas máscaras, as suas manhas. Mas também o seu rigor e a sua competência.

Escolhemos para ilustrar este terreno de diálogo e controvérsia, a figura de Descartes, não só por constituir um marco incontornável do pensamento moderno como também e sobretudo por se tratar de um pensador que nunca se furtou a dialogar, confrontando conceitos e teses. As discussões que ele próprio provocou, oferecendo o seu trabalho ao olhar crítico dos seus pares e respondendo pessoalmente às objecções dos mesmos, dão-lhe um lugar de relevo na tradição dialógica e argumentativa, nem sempre explicitamente presente na filosofia ocidental.

Embora Descartes seja cultor das ciências matemáticas e físicas, no âmbito das quais também travou discussões interessantes, as controvérsias que aqui focamos são de índole filosófica, decorrendo consequentemente de "oposições categoriais e conceptuais dificilmente falsificáveis" 2 . Começaremos, neste artigo, com a polémica que travou com Hobbes. Dela escolhemos o problema do sujeito, com o qual exemplificaremos o confronto de teses irredutíveis, mostrando a dificuldade que há em fazer concessões quando os fundamentos metafísicos, subjacentes às teses, são radicalmente diferentes. Neste caso assistimos a dois discursos paralelos, que se desenrolam permitindo o esclarecimento mútuo de conceitos bem demarcados. Adefesa das teses é acompanhada de atitudes reveladoras de dois estilos diferentes. E a ironia, a condescendência e por vezes mesmo a agressividade que se desprendem do texto das Terceiras Objecções e Respostas são a prova de que ao filosofar não nos limitamos a apresentar argumentos e a procurar justificá-los. Há um revelar do sujeito humano que nos permite entendê-lo na totalidade que ele é, e não apenas como puro espírito.

O relacionamento de Descartes com a Princesa Elisabeth da Boémia é um outro tipo de controvérsia que abordaremos, situando-o, preferencialmente, no plano do diálogo. Trata-se de um posicionamento assimétrico, dado que a eleitora palatina se assume como discípula e é no interior desse estatuto que pede explicações ao mestre. O que nem por isso isenta as suas dúvidas de uma atitude crítica, aliás bastante produtiva quanto ao re-direccionamento que provocou na filosofia cartesiana. Daí termos seleccionado certas passagens da correspondência onde verificamos as dificuldades levantadas por Elisabeth na procura de uma vida boa, na qual corpo e mente se equilibrem.

Finalmente atenderemos ao olhar crítico de Espinosa, que com Descartes aprendeu a filosofar, dele recebendo os instrumentos conceptuais que lhe permitiram escrever a Ética. Trata-se, neste caso, de um discípulo que tentou superar o mestre, procurando "resolver" questões por este deixadas em aberto. Elegemos para ilustrar esta situação o prefácio do livro V da Ética, onde Espinosa dirige fortes críticas ao pensamento cartesiano, particularmente no que respeita ao dualismo e à terapia das paixões.

1 Susanne Langer, Philosophy in a New Key - A study in Symbolism of Reason, Rite, and Art, London, Harvard University Press, p. 8.

2 Fernando Gil, Mimésis e Negação, Lisboa, Imprensa Nacional - Casa da Moeda, 1984, p. 463. O autor procede nesta obra a uma análise da categoria de "controvérsia", situando-a privilegiadamente no plano das teorias científicas. 
Uma mesma dificuldade perpassa estes três pensadores, dificuldade que aliás se levanta a todo o leitor de Descartes: a relação por ele estabelecida entre pensamento e matéria, um pressuposto metafísico com fortes implicações antropológicas. Cada um dos filósofos que iremos tratar aborda esta questão mediante diferentes estratégias. Em Hobbes constatamos o desejo de tornar patente os erros e imprecisões do pensamento cartesiano. $\mathrm{O}$ ataque empreendido é cerrado, com a preocupação de mostrar fraquezas. Descartes responde num mesmo registo dando-nos ocasião para assistir a uma verdadeira peleja argumentativa. Diferente é a posição de Elisabeth cuja pretensão maior é ser esclarecida. Deste modo, coloca as questões quase a medo, admitindo que as dificuldades sentidas residem, todas elas, na sua incapacidade de perceber - "ma stupidité..."”. Mas nem por isso se rende às explicações do filósofo. Antes se cala, passando a um outro assunto. Dos três interlocutores Espinosa é o único que não dialogou directamente com Descartes. Assim as críticas feitas não têm retorno. Não esperando resposta, sublinha as incongruências que constata no pensamento cartesiano como pretexto para nos apresentar uma concepção mais consistente do real, mantendo a terminologia cartesiana mas com ela construindo uma visão do mundo totalmente diferente.

$\mathrm{O}$ choque destes pensadores com o sistema cartesiano, o modo como este contribuiu para a formação ou consolidação de um pensamento próprio em cada um deles, o próprio eco que as críticas tiveram na evolução da obra de Descartes ${ }^{4}$ é mais uma prova da essencial dialogicidade da filosofia, desmentindo o preconceito do autismo dos filósofos.

\section{Dois colegas em luta: a controvérsia com Hobbes}

“(...) i'eusse voulu que cét excellent auteur de nouelles speculations se fust abstenu de publier des choses si vieilles".

Hobbes, Obiection Premiére ${ }^{5}$

"Et pendant que ce philosophe ne peut convenir avec moi de la signification des mots, il ne me peut rien objecter qui ne soit frivole".

Descartes, Obiection Huitiéme, Réponse ${ }^{6}$

No conjunto das Objecções e Respostas, as Terceiras têm um cunho especial, pelo carácter incisivo dos argumentos e pela vivacidade do diálogo, sem qualquer complacência de uma parte e de outra. Estamos perante dois pensadores que directamente se questionam e que por vezes se agridem, num diálogo destituído de retórica e de equivocidade, no qual cada um pretende provar que tem razão. A tónica de Hobbes, a abrir o debate, é de condescendência, pondo em causa, logo de início, a pertinência de algumas teses cartesianas que classifica de velharias - "des choses si vieilles". As respostas de Descartes denotam alguma crispação, ou mesmo impaciência. Verificamo-lo quando o pensador francês assegura já ter explicado suficientemente

3 Carta de Elisabeth a Descartes de 20 de Junho de 1645, AT, III, p. 684.

Usaremos a tradução da correspondência organizada por Adelino Cardoso e Maria Luísa Ribeiro Ferreira, Medicina dos Afectos. Correspondência entre Descartes e a Princesa Elisabeth da Boémia, Lisboa, Celta, 2001, que designaremos por C. Situaremos os textos citados na edição de Charles Adam et Paul Tannery, Paris, Vrin, 1996 que designaremos por AT.

4 Obviamente que neste caso nos referimos a Hobbes e a Elisabeth dado que não houve diálogo directo com Entre Descartes e Espinosa. O primeiro morreu em 1650; Espinosa começou a aprender latim e a estudar filosofia, com Van den Ende, em 1652, rompendo definitivamente com a ortodoxia judaica em 1656, data da sua excomunhão da comunidade.

5 Troisiémes Obiections faites par vn celebre Philosophe Anglois avec les réponses de l'auteur, Obiection Premiére, AT, IX, p. 133.

6 Ob. cit., Obiection Huitiéme, Reponse, ibidem, p. 143. 
certos assuntos sendo irrelevante retomá-los ${ }^{7}$, ou quando considera, tal como fica expresso no excerto acima citado, que as objecções de Hobbes serão sempre frívolas enquanto este não se der ao trabalho de esclarecer o sentido das palavras. A impaciência cresce à medida em que o escrito avança. De facto verficamos que as primeiras objecções, nem sempre as mais importantes, são tratadas com algum desenvolvimento, enquanto que no final do texto ficam por responder questões polémicas e pertinentes cuja "pseudo-solução" é apresentada em poucas linhas.

$\mathrm{Na}$ verdade há desfasamentos de parte a parte. Alguns deles devem-se a dificuldades interpretativas ou mesmo a leituras incorrectas. Assim, na Objecção Terceira, Hobbes critica Decartes por este considerar inseparáveis o sujeito e as suas diferentes formas de pensamento, baseando-se exclusivamente no texto latino, algo ambíguo, e esquecendo a clarificação posteriormente feita no texto francês das Meditações. É verdade que na primeira versão das mesmas, Descartes pergunta: "quid est quod a mea cogitatione distinguatur?"8 o que teria como imediata resposta: o sujeito pensante. É esta a leitura (algo literal e apressada) que Hobbes faz do texto cartesiano, considerando irrelevante a questão levantada pelo seu autor. Só que na tradução francesa das Meditações Descartes é muito mais explícito, tornando óbvia a identificação do sujeito e dos seus vários modos de pensar: "Y a-t-il aussi aucun de ses attributs qui puisse estre distingué de ma pensée ou qu'on puisse dire estre séparé de moy mesme?"'. Baseando-se nesta segunda versão, o filósofo francês considera que a crítica hobbesiana não tem qualquer sentido.

As dificuldades de interpretação são recorrentes e manifestam-se em cada um dos autores. Assim, na Resposta à Objecção Sexta é a vez de Descartes não compreender a dúvida levantada por Hobbes quanto à relação entre representações e volições. Na verdade, para explicar um acto decorrente do medo ou de uma volição, o filósofo inglês considera ser imprescindível incluir nele o movimento corpóreo. Para o autor do Leviatã, as volições e os medos são pensamentos acompanhados de uma acção corporal. Descartes considera que é a consciência de determinadas representações que as identifica como volições ou como medos. Para ele esta tese é tão evidente que ridiculariza a pergunta de Hobbes, não se dignando mesmo responder-lhe.

Os desentendimentos também se traduzem em pequenas quezílias a propósito do significado dos termos, tarefa que, segundo Descartes, Hobbes nunca empreendeu, condenando-se consequentemente a uma incompreensão do pensamento cartesiano $^{10}$. Por vezes há acusações implícitas de má fé, como acontece na Resposta à Objecção Quinta, na qual o filósofo francês considera já ter falado suficientemente do tema em causa, ou seja, da ideia de Deus em nós.

Para além destas fricções há divergências mais graves, provocadas pelos pressupostos filosóficos que cada pensador toma como ponto de partida, e que o levam a perspectivar de um modo original as grandes questões de que se ocupa. De onde a dificuldade do diálogo. Descartes é particularmente sensível a essée afastamento e isso nota-se no próprio ritmo do texto. A partir da Objecção Sexta as respostas são breves, revelando por vezes alguma irritação, como se o autor das Meditações considerasse inútil dialogar com alguém que não compreende a sua linguagem nem tem qualquer sintonia com as suas posições. De facto, no que respeita aos filosofemas mais pregnantes do texto cartesiano, como é o caso do sujeito pensante, do estatuto das ideias, da existência de Deus ou da verdade e do erro, o desentendimento é total.

7 Objection Neuviéme, Reponse, AT, p. 144; Obiection Onziéme, Reponse, AT, p. 147; Obiection Catorziéme, Reponse, AT, p. 151.

8 Meditatio Secunda, AT, VII, p. 29.

9 Méditation Seconde, AT, IX, p. 22. 
Não iremos considerar o texto das Terceiras Objecções e Respostas no seu todo; apenas destacaremos nele o tema do sujeito humano e do pensamento. É uma questão sobre a qual os dois autores polemizam e que nos pareceu útil para perceber o paradgima em que cada um dos filósofos se situa. Na verdade, as críticas de Hobbes e as explicações de Descartes permitem traçar com nitidez o materialismo e nominalismo do primeiro e o espiritualismo e substancialismo do segundo.

A abordagem do tema em causa é feita logo a partir das Objecção Segunda. Nela Hobbes contesta a identificação do sujeito com as suas faculdades, troçando da expressão cartesiana "eu sou pensante" e considerando-a permutável com uma infinidade de outras situações em que o eu se pode encontrar, igualmente válidas para o definir. Se defino o sujeito como "pensante" também o posso fazer como "passeante". Em qualquer dos casos incorro num erro que é confundir o sujeito com as suas faculdades e acçôes. A crítica dá azo a que Descartes reafirme o seu substancialismo, perfeitamente evidente quando o autor das Meditações reitera o sujeito como "res cogitans", dando ao pensamento o carácter de atributo essencial. Este pode por vezes ser considerado como acção ou como faculdade, mas é sempre, em primeiro lugar, uma coisa ou uma substância.

O tema do sujeito e das suas faculdades é retomado na Objecção Terceira, que, como vimos, assenta num problema de tradução do latim. Mas para Hobbes é sempre confusa a identificação cartesiana do sujeito e das suas acções, o que para Descartes é uma evidência.

Também a essência do sujeito é motivo de discórdia. O filósofo inglês define-o, à semelhança de todos os outros corpos, recorrendo à matéria que o constitui. Mesmo aceitando que o sujeito é essencialmente pensamento, considera abusivo concluir que este é espiritual. Hobbes sustenta que "vne chose qui pense est quelque chose de corporel"11 e fundamenta esta tese justificando que os sujeitos de todos os actos só se podem explicar por uma "razão de matéria" ou "razão corporal" 12 . Não podemos separar o pensamento de uma matéria que pensa. Assim, todo o pensamento é necessariamente material, quer se processe a partir dos objectos, quer das ideias ou imagens dos mesmos ${ }^{13}$. Estas, como noutras obras defende, são nomes, ou seja, marcas convencionais que nos permitem efectuar operações sobre as coisas. O raciocínio é uma espécie de cálculo ${ }^{14}$ e os elementos que nele entram têm uma base material, que em última instância remonta ao nosso aparelho fonador, emissor de sons.

Compreende-se como esta concepção seja absurda para Descartes, para quem interessam as coisas significadas e não os nomes das mesmas ${ }^{15}$. Nada mais estranho ao autor do Discurso do Método do que o nominalismo hobbesiano e a convencionalidade que este filósofo atribui à ciência e aos conceitos científicos. $\mathrm{O}$ registo de Descartes é a verdade e propõe-se alcançá-la recorrendo a um método adequado que nos permita aceder às essências. Hobbes contenta-se com a validade; as fronteiras que propõe para a ciência e para o conhecimento restringem-se à coerência e adequabilidade, quer das sensações relativamente aos objectos percebidos, quer das ideias relativamente às possíveis cadeias de raciocínio nas quais se inserem. De onde a valorização da crença

10 É o caso das Objecções Sétima e Oitava às quais Descartes praticamente nem responde.

11 Hobbes, Obiection Seconde, AT, IX, p. 135.

12 "raison de matiére"; "raison corporelle"; Ibidem.

13 Uma outra linha de discordância tem a ver com o facto de Hobbes identificar imagem e ideia, enquanto que para Descartes esta última é essencialmente representação.

14 "reason (...) is nothing but reckoning...

Leviathan, cap. V, em The Collected Works of Thomas Hobbes, (CWTH), ed. William Molesworth, rprt. Aalen, Scientia, 1971, III, I, p. 30.

15 Descartes, Obiection Quatriéme, Réponse, AT, IX, p. 139. 
como horizonte em que a ciência se enquadra, contrastando com o objectivo cartesiano de alcançar a verdade, mediante certezas evidentes.

A discussão reacende-se no final do texto das Terceiras Objecções e Respostas, quando nas Objecções Décima Terceira e Décima Quarta se analisa o problema da verdade e dos critérios que esta pressupõe. Enquanto para Descartes, a clareza e a distinção de certos conceitos se impõem com tal evidência que ninguém, são de espírito, os poderá recusar, para Hobbes a clareza é uma metáfora, incompatível com uma argumentação rigorosa ${ }^{16}$. Se o sábio defende os seus conceitos e teses pela evidências dos mesmos, também o obstinado declara ver claramente os resultados a que chega, e as mais das vezes estes são erróneos. Continuam em jogo dois conceitos diferentes de verdade. Uma, a cartesiana, atribui-lhe uma tal força que obriga todos os espíritos que ă alcançaram a ela aderir, rendendo-se à sua evidência. Como mais tarde dirá Espinosa, que neste ponto é plenamente cartesiano: "est enim veritas index sui, \& falsi" "17. Outra é a perspectiva hobbesiana, sustentando que a adesão a uma "verdade", adesão essa que se circunscreve sempre a um estatuto de crença, depende totalmente da validade dos raciocínios que a ela conduziram, os quais nos obrigam, pela justeza do seu encadeamento, a aceitar um determinado resultado. Hobbes defende na Objecção Décima Quarta que todos os conceitos, mesmo os matemáticos, são construídos. Não há qualquer imposição dos mesmos ao nosso espírito dado que é o sujeito que os fabrica, a partir das imagens que recebe dos objectos. O contraste de posicionamentos é mais uma vez patente, ficando claro o inatismo cartesiano e o sensualismo de Hobbes. É uma objecção a que Decartes não responde, considerando que a questão já foi suficientemente "refutada e rejeitada"18.

Poderíamos retomar o texto das Terceiras Objecções e Respostas, considerandoo agora a partir de outras dissidências. Mas seja a controvérsia analisada a partir do sujeito, como até aqui fizemos, seja de Deus ou das ideias como poderíamos também fazer, há sempre um mesmo resultado: o traçar de dois caminhos paralelos que progressivamente se vão revelando e clarificando. Na verdade, como atrás referimos, grande parte dos desentendimentos constatados têm na sua origem um modo diferente de validar o conhecimento e de fazer filosofia.

Hobbes questiona toda a teoria que não se submeta ao critério da sensação ou do raciocínio. Para ele é um dado incontestável que a ciência se faz com nomes, ou seja, designações convencionais, porque convencionadas, que atribuímos ao resultado quer das nossas sensações quer das nossas deduções ${ }^{19}$.

Grande parte dos pressupostos sobre os quais o autor das Meditações edifica o seu pensamento, assenta na intuição. A dedução consiste num encadeamento de intuições e a sua justificação deriva dos limites da memória humana ${ }^{20}$. É uma posição que o filósofo inglês considera insustentável pois para ele tais intuições carecem de justificação e como tal não são critério suficiente para fundamentar a ciência.

O confronto destes dois modos de filosofar não pretende destacar um ganhador e um perdedor mas sim fazer-nos perceber que a rigidez e completude com que por vezes se apresentam os sistemas filosóficos, nomeadamente os da modernidade, têm na sua base uma génese oculta, fruto do dinamismo argumentativo que os originou e fez crescer.

16 Hobbes, Obiection Treisiéme, AT, IX, p. 149.

17 Espinosa, Carta a Alberto Burgh, G. IV, p. 320.

18 “(...) \& ce qui est dit ici (...) a desja esté cy-devant assez réfuté \& reietté". Descartes, Obiection Qvatorziéme, Réponse, AT, IX, p. 151.

19 Hobbes, Human Nature, cap. V, § 4, CWTH, IV, p. 21.

Leviathan, cap. V, CWTH, III, I, p. 36.

20 Descartes, Regulae ad Directionem Ingenium, Regula III, AT X, pp. 368-70. 


\section{O diálogo mestre - aluna: as cartas de Elisabeth}

Se na controvérsia entre Hobbes e Descartes pudemos constatar uma certa animosidade, o diálogo com Elisabeth decorre num clima diferente. As cinquenta e oito cartas que constituem esta correspondência, demonstram de parte a parte, serenidade e respeito. No caso de Descartes, quase roçando a subserviência, no de Elisabeth uma humildade extrema. Na primeira carta que endereça ao filósofo, a Princesa escreve: "senti-me igualmente tocada pela caridade de quererdes comunicar com uma pessoa ignorante e indócil..."21. Descartes responde: "O favor com que Vossa Alteza me honrou ao transmitir-me por escrito os seus pedidos, é maior do que alguma vez ousara esperar" 22 . E esta troca de amabilidades é uma constante que se mantém da primeira à última das cartas.

Elisabeth interroga-se sobre a arte de viver feliz, procurando atenuar os padecimentos do seu corpo, de modo a obter a tranquilidade da alma que lhe permita usufruir de uma vida boa. Segue como estratégia a assunção da sua fraqueza intelectual - "uma pessoa estúpida como eu" (cartas de 20 de Junho de 1643 e 28 de Outubro de 1645 ), bem como da sua condição de mulher - "um corpo tão fraco" (carta de 24 de Maio de 1645$)^{23}$. Mas a severidade com que se auto-classifica, não impede a Princesa de interrogar Descartes, dele exigindo esclarecimentos para as suas dúvidas. O que obriga o filósofo a aprofundar certos conceitos e a rever ou reavaliar outros. É para responder às consultas da "doente" Elisabeth que o "médico" Descartes se debruça sobre o corpo e sobre o papel que a este cabe na obtenção da felicidade. O sujeito humano, até então encarado como intelecto puro, é repensado na sua dualidade essencial pois a medicina do corpo tem inegáveis implicações sobre a cura dos males da alma. Os afectos assentam numa base fisiológica que urge estudar e as paixões da alma são reguladas pelo conhecimento do corpo.

Com Elisabeth Descartes é levado a reflectir sobre a felicidade. Esta processa-se neste mundo, no qual somos um dualidade complexa e não puros espíritos. É por isso que as actividades exclusivamente intelectuais são consideradas raras e difíceis. Daí o conselho dado pelo filósofo quanto ao tempo que devemos dedicar ao lazer e à distracção do espírito, seguindo-se a confissão, na carta de 28 de Junho, de que ele próprio poucas horas dedica à metafísica.

O diálogo com Elisabeth obriga o filósofo a rever algumas das traves mestras do seu pensamento, questionando evidências e trilhando novas orientações, nomeadamente no que respeita à antropologia e à moral. É assim que ao dualismo da "res cogitans" e da "res extensa" vem juntar-se um outro princípio básico, constituído pela união de ambas as substâncias. Uma das maiores "surpresas" que esta correspondência nos apresenta, passa precisamente pelo relacionamento destes dois princípios na consideração de um homem completo. Este é anunciado na Sexta Meditação, mas as razões aí apresentadas são pouco convincentes. De facto, depois de demonstrada racionalmente a nossa essência espiritual, os argumentos quanto ao poder da alma sobre o corpo são frágeis e justificam-se apenas pelo recurso a vivências. Elisabeth sente essa dificuldade e pede ao filósofo "uma definição da alma mais particular do que na vossa Metafísica, ou seja, da sua substância separada da sua acção, do pensamento"24.

Diferentemente do tratamento dado às questões levantadas por Hobbes, geralmente consideradas como irrelevantes e demonstrativas da pouca atenção de quem as formulou, Descartes admite a pertinência da dúvida: "E posso dizer com verdade

21 Carta de Elisabeth a Descartes, $6 / 16$ de Maio de 1643, C., p. 29, AT, III, p. 660.

22 Carta de Descartes a Elisabeth, 21 de Maio de 1643, C., p. 31 , AT, III, p. 663.

23 A estratégia seguida por Elisabeth e a eficácia da mesma foram por nós abordadas no prefácio da referida tradução da correspondência. Vj. Maria Luísa Ribeiro Ferreira, "Consultando Descartes. As Cartas de Elisabeth", p. 9.

24 Carta de Elisabeth a Descartes de 6/16 de Maio de 1643, C., p. 30, AT, III, p. 661. 
que a questão que Vossa Alteza propõe me parece ser aquela que mais fundamente se me parece colocar, no seguimento dos escritos que publiquei"25.

A explicação que o filósofo adianta é esclarecedora e abre um novo capítulo nas investigações cartesianas, ultrapassando o dualismo estrito. Na verdade, apresenta três (e não duas) noções básicas a partir das quais os homens têm o direito de pensar e fazer derivar todos os conhecimentos: a extensão, o pensamento e a união de ambos. São noções "originais sobre cujo padrão formamos todos os nossos outros conhecimentos"26. Fica assim delimitado o terreno em que nos é lícito pensar o real pois a cada uma dessas noções pertence uma categoria ontológica demarcada, dotada de leis específicas, sujeita a métodos próprios, usando linguagens diferenciadas: "Considero (...) que toda a ciência dos homens consiste apenas em distinguir bem estas noções e em atribuir cada uma delas somente às coisas a que pertencem"27.

Nesta carta de 21 de Maio, Descartes sustenta que tão importante é para o conhecimento da alma o facto de ela ser pensante como o de estar unida ao corpo, o que lhe dá um toque de materialidade. O filósofo admite o paradoxo desta situação, usando na carta seguinte, de 28 de Junho, uma imagem que ajuda a compreender a alma enquanto parte do composto: “(...) peço-lhe que atribua livremente essa matéria e essa extensão à alma; porquanto isso mais não é do que concebê-la unida ao corpo"28. Mais tarde, nas Paixões da Alma, esclarecerá melhor esta questão, fazendo corresponder a alma à estrutura e organização de um corpo, que a mesma abandona quando tal estrutura se dissolve ${ }^{29}$.

Na carta de 21 de Maio o filósofo reitera a existência de três ordens diferentes do real, cada uma das quais conduz a um tipo de conhecimento. Duas delas permitem-nos aspirar à verdade enquanto que a terceira se limita ao plano do provável. De facto, no que respeita ao composto humano, estamos perante um mundo confuso e obscuro, no qual tomamos como critério a acção eficaz. A alma quando relacionada com o corpo leva-nos a agir, mesmo que não tenhamos ideias claras e distintas. A moral circunscreve-se ao bem e não à verdade, o que a impede de aceder ao estatuto de ciência lógico dedutiva, à maneira da matemática e da física. Os nossos actos são avaliados em função do bem estar, da felicidade, ou de outros critérios não dependentes da evidência imediata mas antes decorrentes de uma ponderação sobre as consequências do nosso agir ${ }^{30}$.

Que conclusões podemos tirar da consideração dos três princípios primitivos enunciados nas primeiras cartas de Descartes a Elisabeth?

Em primeiro lugar, a já referida superação do dualismo ontológico, pela existência de três ordens de realidade: a dos corpos, a das mentes e a dos compostos de ambos. Do que resulta passarmos a considerar uma tripla entrada na epistemologia: os corpos subordinam-se às leis' físicas da matéria e estudam-se através do entendimento e da imaginação. As almas, enquanto consideradas na sua actividade pensante, conhecem-se pelo entendimento. O composto humano, esse mundo híbrido, participa das leis dos corpos e da liberdade das mentes mas não dispensa o recurso a vivências, a sentimentos, a sensações e a toda a gama passional que assinala a união. Se queremos pensar correctamente temos que respeitar a especificidade desses três domínios, circunscrevendo-nos ao que a cada um pertence. Se nos colocamos no registo

28 Carta de Descartes a Elisabeth, 28 de Junho de 1643, C., p. 38, AT, III, p. 694.

29 Les Passions de l'Âme, I, art. ${ }^{\circ} 30$, AT, XI, p. 351.

Há um exemplo esclarecedor na Carta de Descartes a Morus de 5 de Fevereiro de 1649, onde Descartes compara a alma ao fogo num ferro em brasa, mostrando como está nele mas não faz parte dele.

30 Oregisto "não científico" da moral aparece nitidamente expresso na Carta a Elisabeth de 4 de Agosto de 1645, no Tratado das Paixões da Alma, art. 48 e no prefácio dos Princípios. 
metafísico, é-nos exigido um "ascetismo intelectual" e devemos considerar o corpo como obstáculo ${ }^{3 !}$. Se nos debruçamos sobre os corpos, a imaginação ajuda-nos a visualizá-los. Se elegemos o domínio antropológico, visamos o homem total, com as suas paixões e o seu desejo de saúde e felicidade, domínios em que os sentidos e a imaginação têm um papel inegável.

Pelo facto de estar unido à alma, o corpo humano é reapreciado naquilo que tem de próprio: o sentimento. Surge uma nova ciência, a psico-somática, na qual cada um dos elementos que compõe o homem tem o seu papel. Na carta de Setembro de 1646, Descartes defende que a saúde do corpo e a presença de objectos agradáveis ao mesmo são determinantes para manter o equilíbrio que nos faz felizes. Há que atender à vivência que temos do corpo próprio, relativamente às sensações que este experimenta e à influência dos objectos externos. As leis da física são insuficientes para conhecer o composto humano pois este é um indivíduo, e mais do que um indivíduo é um sujeito. O que significa não bastar, para o seu total conhecimento, considerá-lo no que tem de comum com os outros corpos, tal como também é incompleto entendê-lo como puro espírito.

Se o diálogo desenvolvido com a sua correspondente leva Descartes a ultrapassar uma concepção mentalista de homem, as interrogações da Princesa também têm um papel determinante na consolidação da moral cartesiana. Nas obras que Elisabeth conhece e a partir das quais levanta questões - O Discurso do Método e as Meditações Metafisicas - a ética tem pouco peso. Bastam ao filósofo as regras de uma moral provisória nitidamente influenciada pelo estoicismo ${ }^{32}$. E é precisamente para esta corrente que o filósofo pretende orientar a Princesa, propondo-lhe o estudo dialogado de uma obra de Séneca: De Vita Beata.

A escolha dos estóicos não é arbitrária, mostrando a boa conta em que o filósofo os considera. É possível que ao propor o pensamento moral dos antigos de modo a "tornar esses preceitos perfeitamente nossos e dispor-nos a praticá-los" 33 , o autor se tenha querido colocar num terreno neutro, já trabalhado por outros e, como tal, não demasiado comprometedor. Só que Elisabeth se desinteressa deste estudo, preferindo continuar o seu diálogo num registo cartesiano, que ela classifica de muito mais natural e metódico ${ }^{34}$. Descartes é sensível à lisonja e desiste do projecto. Aliás já na carta de 4 de Agosto admite que foi precipitado na escolha e considera a doutrina dos estóicos "não (...) suficientemente exacta para merecer ser seguida" 35 . Assim, adopta uma posição crítica relativamente a Séneca e demarca-se da identificação estóica entre beatitude e soberano bem; para ele a primeira decorre do segundo, como consequência da sua posse. À exigência de Zenão que chama virtuosos aos que se desligam do corpo, Descartes contrapõe uma atitude mais consentânea com a fraqueza natural dos homens pois “(...) só melancólicos ou espíritos completamente desligados do corpo é que puderam ser seus servidores" 36 . A distância relativamente aos estóicos também se faz

31 O termo "ascetismo intelectual" é usado por Martial Guéroult em Descartes selon l' Ordre des Raisons, Paris, Aubier, 1994, Vol. II, p. 239.

32 Entre os comentadores que se interessaram pelas influências estóicas em Descartes destacamos: Victor Brochard, "Descartes Stoïcien. Contribution à l' histoire de la philosophie cartésienne", em Etudes de philosophie ancienne et de philosophie moderne, Paris, Vrin, 1926, pp. 320-326; Pierre Mesnard, Essai sur la morale de Descartes, Paris, 1936; A. Bridoux, Le stoicisme et son influence, Paris, Vrin, 1966; Gilles Olivo, "Une patience sans espérance? Descartes et le stoïcisme", em AAVV, Le stoicisme au XVIe et XVIIe siècles, Caen, Presses Universitaires de Caen, 1994, pp. 131-146.

33 Carta de Descartes a Elisabeth, 21 de Julho 1645, C., p. 68, AT, IV, p. 252.

34 Carta de Elisabeth a Descartes de 16 de Agosto de 1645.

35 Carta de Descartes a Elisabeth, 4 de Agosto de 1645, C., p. 70, AT, IV, p. 263.

36 Carta de Descartes a Elisabeth de 18 de Agosto de 1645, C., p. 77, AT, IV, p. 276. 
sentir no papel atribuído à vontade no que respeita à virtude: “(...) seguir a virtude, isto é, ter uma vontade firme e constante do que julgamos ser o melhor..."37.

$\mathrm{O}$ abandono do estoicismo é definitivamente assumido na carta de 15 de Setembro, onde o filósofo escreve: "É por isso que, sem me deter agora a seguir Séneca, procurarei tão só explicar a minha opinião sobre esta matéria"38. É uma perspectiva que pressupõe quatro pontos básicos, contrastantes com o pensamento estóico e esclarecedores das tẹses cartesianas. Vejamos cada um deles.

Em primeiro lugar temos a existência de um Deus misericordioso e infinitamente bom, facto que leva o homem a uma atitude de confiança pois nada há de inevitável ou de definitivo nos seus actos, sempre sujeitos a um olhar benevolente que conhece em profundidade as intenções de cada um. À "paciência sem esperança", dos estóicos ${ }^{39}$, Descartes contrapõe um Deus providente e amoroso, que nunca nos deixa desesperar.

O segundo ponto reitera a superioridade da alma sobre o corpo, o que implica um distanciamento dos bens materiais, pela consciência da "infinidade de contentamentos que se não encontram nesta vida"40. É essa superioridade que leva Descartes, noutros escritos, a explorar o papel da vontade na afirmação individual. Como reforça em carta a Cristina da Suécia, a vontade é o único bem de que podemos dispor livremente e a virtude consiste em fazer, de um modo fịrme, aquilo que pensamos ser o melhor. A vontade aproxima-nos de Deus e é "do bom uso do livre arbítrio que vem o maior e mais sólido contentamento da vida"4l. Ora a tomada firme de uma resolução e a necessidade de nos mantermos fiéis às opções feitas constituem um leit-motif do diálogo com Elisabeth, a quem Descartes aconselha a ser resoluta pois "só a irresolução causa lamentações e arrependimentos" ${ }^{\prime \prime 2}$.

Os dois últimos pontos prendem-se com a infinitude do Universo e com a pequenez dos homens. Enquanto partes do todo, devem sujeitar-se às leis que o regem, sem a pretensão de as conhecer integralmente. Há uma solidariedade entre tudo quanto existe, o que faz o filósofo concluir, antecipando Espinosa, que "devemos preferir sempre os interesses do todo, de que somos parte, aos da nossa pessoa em particular"43.

As questões de Elisabeth obrigam Descartes a traçar um rumo ético próprio, ou seja, a abordar as paixões da alma e a acrescentar a um método que ensina a pensar bem, outro que ajuda a bem viver. E se o primeiro coloca a verdade como meta, o segundo estrutura-se em torno do conceito de felicidade. Note-se que há um paralelismo entre os percursos epistemológico e ético pois ambos visam um ideal e traçam o caminho que o permite alcançar. Diferente é no entanto o objecto sobre o qual cada um se debruça; no registo epistemológico, analisam-se as diferentes percepções, numa tentativa de encontrar um critério de validação das mesmas; é central o tema das ideias. Na moral, estão em primeiro plano as paixões e os sentimentos; o objectivo é extrair deles o maior contentamento possível. E se nas obras de cariz epistemológico se pretende combater o erro e chegar à verdade, nas de teor ético visa-se curar os afectos nocivos e cultivar os que permitem viver uma vida feliz.

37 Ibidem, p. 78, AT, p. 277.

38 Carta de Descartes a Elisabeth de 15 de Setembro de 1645, C., p. 87, AT, IV, p. 291.

39 O termo é usado por Leibniz, Philosophische Schriften, ed. Gerhardt, Hildesheim, 1965, t. IV, pp. 298-299.

40 Carta de Descartes a Elisabeth de 15 de Setembro de 1645, C., p. 87, AT, IV, p. 292.

41 Carta de Descartes a Cristina da Suécia, 20 de Novembro de 1649, AT, V, p. 84.

A temática da moral e das paixões da alma inicia-se na correspondência com Elisabeth e culmina posteriormente nas cartas que o filósofo indirectamente dirigiu a Cristina da Suécia, por intermédio de Chanut, bem como na célebre epistola sobre a Beata Vita que directamente endereça à Rainha.

42 Carta de Descartes a Elisabeth, 15 de Setembro de 1645, C., p. 89, AT, IV, p. 295.

43 Ibidem, C., p. 88, AT, IV, p. 293. 
Os conselhos de Descartes a Elisabeth que de início parecem verdades de senso comum, vão-se progressivamente transformando numa teoria das paixões, lançando as bases do que posteriormente o Tratado sobre as mesmas irá desenvolver.

São as perguntas da Princesa que levam o pensador francês a aprofundar a génese e o mecanismo das paixões. A 13 de Setembro de 1645, pede ao filósofo que precise o seu conceito de paixão, exigindo uma definição rigorosa ${ }^{44}$. Descartes não satisfaz imediatamente esse desiderato, mas na carta de 6 de Outubro, particularmente importante para o esclarecimento de conceitos éticos fundamentais, a paixão é apresentada nos seus diferentes cambiantes ${ }^{45}$. Assim, há um sentido lato que inclui todos os pensamentos produzidos na nossa alma sem o concurso da vontade e há um sentido restrito que circunscreve a paixão aos pensamentos provocados pela agitação dos espíritos animais. A paixão identifica-se com a emoção - "(...) a emoção, na qual unicamente reside a paixão..." ${ }^{\prime 46}$ - tema que será retomado e desenvolvido no Tratado, onde peremptoriamente se afirma que embora possamos considerar as paixões como percepções ou sentimentos, o que melhor as identifica é o facto de serem emoções ${ }^{47}$.

As considerações sobre a paixão, feitas nas cartas, são extremamente importantes por nos permitirem passar de uma perspectiva meramente descritiva e explicativa, para outra, normativa e, consequentemente, moral. Neste registo, as paixões são consideradas boas, indispensáveis à vida ${ }^{48}$ e o homem é responsável pelo controlo das mesmas, que consegue empreender através da vontade. Esta não actua directamente, manifestando-se num trabalho sobre as representações, substituindo umas por outras de modo a minorar os efeitos de emoções nocivas (excessivas ou desajustadas) e provocando outras, mais eficazes para um equilíbrio do todo.

Contrariando os receios de Elisabeth que se queixa das paixões que a perturbam e a impedem de ser feliz, a visão que Descartes traça é optimista. Se todo o homem pode aspirar ao conhecimento verdadeiro desde que use o método adequado para tal, também é válida a pretensão à felicidade, desde que conheça o funcionamento e génese das paixões da alma, ou seja, a dependência desta relativamente ao corpo. Deste modo, os conhecimentos médicos tornam-se importantes para o bem estar dos homens, constituindo-se a medicina como primeiro patamar que conduz à moral ${ }^{49}$.

Chanut e Elisabeth foram os interlocutores de Descartes que mais o pressionaram em ordem ao aprofundamento de temas éticos. É pela correspondência com eles trocada que percebemos a filiação da moral cartesiana na física bem como na medicina. A Chanut o filósofo escreve: "a noção da física tal e qual a tentei adquirir, serviu-me enormemente para estabelecer fundamentos certos na moral" 50 . Com Elisabeth fica clara a interdependência entre medicina e moral, na medida em que a primeira conduz à felicidade: "não há ninguém que não deseje tornar-se feliz mas muitos não conhecem os meios de o fazer; e muitas vezes a indisposição que está no corpo impede que a vontade seja

44 "Queria ainda ver-vos definir as paixões, afim de as conhecer bem".

Elisabeth a Descartes, 13 de Setembro de 1645, C., p. 86, AT, IV, p. 289.

45 Nesta carta o filósofo debruça-se sobre o soberano bem, contrasta beatitude e contentamento, paixão e juízo, acção e paixão e teoriza as paixões, Vj. Descartes a Elisabeth, 6 de Outubro de 1645, C., pp. 92-98, AT, IV, pp. 304-317.

46 Ibidem, C., pp. 95-96, AT, IV, pp. 311-313.

47 Passions de l'Ame, art. ${ }^{\circ} 28$.

48 É uma temática que Descartes retoma nas cartas a Chanut e à Rainha Cristina da Suécia, bem como em Passions de l' Âme, art.os 211 e 212.

49 Ressalvem-se dois aspectos particularmente curiosos que constam da correspondência: 0 carácter terapêutico da alegria (Cartas de 4 a 18 de Setembro de 1645) e o papel positivo da imaginação (Carta de 6 de Outubro de 1645).

Ulteriores desenvolvimentos efectuados por Descartes sobre o tema da paixão, remetem para a importância da infância como tempo determinante para as paixões se começarem a definir Vj. carta a Chanut, 1 de Fevereiro de 1647.

50 Carta de Descartes a Chanut, 15 de Junho de 1646, AT, IV, p. 441. 
livre" ${ }^{\text {"1 }}$. Inegavelmente que a saúde é um bem do corpo e a moral um bem da alma. Mas a segunda carece do primeiro para melhor viver. Na carta de Maio/Junho de 1645 o filósofo defende que a saúde é um bem precioso que devemos cultivar; a 6 de Outubro confirma esta tese, acusando de irracionalidade os que desprezam a vida e o bem estar do corpo. Daí a atenção aos males da sua correspondente pois "nada de mais horrível do que estar ligada [a alma] a um corpo que a priva completamente da liberdade" ${ }^{52}$. Se a epistemologia de Descartes prescinde do corpo para alcançar a verdade, a sua moral precisa dele para aspirar a uma beata vita.

As questões da Princesa levaram Descartes a construir uma moral que amplifica o sujeito humano, obrigando o filósofo a encarar o homem total: "o homem, ou seja, o espírito enquanto unido ao corpo" 53 . Trata-se de uma moral da "natureza humana", realisticamente considerada enquanto ancorada num corpo cuja saúde e bem estar é importante manter pois os prazeres do corpo são absolutamente necessários para a realização de cada um.

Assim, o diálogo com Elisabeth recupera o homem total, situa as paixões no coração da ética e deixa definitivamente de a considerar como provisória.

\section{O discípulo ultrapassa o mentor-Espinosa e as paixões ${ }^{54}$}

“(...) e que assim os fundamentos das ciências, encontrados por Descartes, e o edifício que sobre eles ergueu não bastam para desenrolar e resolver todas as questões e as mais dificeis que se encontram na Metafísica".

Ludwig Meyer, prefácio a Renati Descartes Principiorum Philosophiae ${ }^{55}$.

É sabido que Espinosa se iniciou tarde na filosofia, sendo Hobbes e Descartes os pensadores que mais o influenciaram. No que respeita ao primeiro, o apreço é grande e manifesta-se de um modo explícito numa carta a Jarig Jelles onde proclama uma sintonia quase total, nomeadamente no plano político ${ }^{56}$. Quanto a Descartes, há uma certa ambivalência. Inegavelmente que dele recebeu quer o aparato conceptual que lhe permitiu construir um pensamento filosófico próprio, quer as ideias claras e distintas como critério de verdade, quer o "mos geometricus" de quem foi o verdadeiro executor. Não por acaso a sua primeira incursão no campo da filosofia foi a apresentação do pensamento. cartesiano, num escrito revelador da alta conta em que tem o autor das Meditações. No prefácio de Ludwig Meyer, aprovado (e talvez mesmo redigido) por Espinosa, o pensador francês é classificado como "o astro mais brilhante do nosso século", aquele que "colocou os fundamentos inamovíveis da filosofia" ${ }^{57}$. Mas esta visão encomiástica não

s1 Carta de Descartes a Elisabeth, 1 de Setembro de 1645, C., p. 81, AT, IV, p. 282.

52 Ibidem, C., p. 82, AT, IV, p. 82.

53 Ibidem.

54 O texto que se segue retoma alguns dos tópicos apresentados na comunicação "Espinosa, Descartes e Elisabeth - uma busca comum sobre o governo dos afectos", feita no Congresso Internacional El gobierno de los afectos en Spinoza, realizado em Madrid, na Universidade Complutense, em Fevereiro de 2001.

55 "(...) atque adeo scientiarum fundamenta a Cartesio eruta, et quae iis ab ipso superaedificata sunt, non sufficere ad omnes ac difficilimas, quae in Metaphysicis ocurrunt, quaestiones enodandas atque solvendas".

Prefácio de Ludwig Meyer a Renati Descartes Principiorum Philosophiae, em Spinoza Opera, ed. Carl Gebhardt (G), Heidelberg, 1972, G. I, pp. 132-133.

s6 "Quantum ad Politicam spectat, discrimen inter me, et Hobbesium, de quo interrogas, in hoc consistit, quod ego naturale Jus semper fartum tectum conservo, quodque Supremo Magistratui in qualibet Urbe non plus in subditos juris, quam juxta mensuram potestatis, qua subditum superat, competere statuo, quod in statu Naturali semper locum habet".

Ep. L a Jarig Jelles, em Spinoza Opera, G. IV, pp. 238-9.

57 " “...) splendissimum illud saeculi nostri jubar Renatus Descartes (...) Philosophiae fundamenta inconcussa eruit".

Renati Descartes Principiorum Philosophiae, G. I, p. 128. 
é isenta de críticas, sendo as falhas do pensador francês apontadas no final do próprio prefácio em que se lhe faz o elogio.

Reencontramos a mesma atitude de louvor e crítica no prefácio do livro $\mathrm{V}$ da Ética. Embora neste passo Espinosa apelide o autor das Meditações de "vir clarissimus" ${ }^{\prime 8}$, não deixa de lhe apontar falhas, nomeadamente no que respeita aos temas do dualismo e das paixões da alma. São essencialmente estes dois problemas que, segundo o filósofo judeu, Descartes deixou em aberto, ou mal resolvidos, $\cdot \mathrm{e}$ que ele, Espinosa, se propõe retomar. As dúvidas que levanta e o modo como procura responder-lhes tornam patente a segurança de um discípulo que, tendo-se autonomizado do mestre, constrói um sistema próprio, um mundo que tanto em termos antropológicos como em termos metafísicos é profundamente diferente da filosofia cartesiana na qual inegavelmente se inspira.

Seleccionámos o livro V da Ética como texto significativo do afastamento de Descartes, não só porque, como atrás dissemos, ele é explicitamente referido no Prefácio, mas porque no decurso desta "outra parte da Ética" 59 fica patente a existência de dois projectos vivenciais e filosóficos distintos: o cartesiano colocando como objectivo viver a vida sem temer a morte; o espinosano pretendendo viver neste mundo a eternidade ${ }^{60}$.

No prefácio do livro V Espinosa propõe-se tratar dos afectos, mostrando até que ponto os conseguimos dominar, ou melhor, confirmando teses que entretanto já defendera em passos anteriores ao reconhecer que a razão não tem sobre eles um poder absoluto. É aqui que o ataque a Descartes é mais directo: o filósofo francês é concretamente mencionado e as críticas, por vezes perpassadas de ironia, visam quer os seus pressupostos teóricos quer a sua (impossível) aplicação prática.

As teorias cartesianas no que respeita à paixão começam por ser identificadas com as teses estóicas e consideradas falsas. É uma aproximação algo injusta até porque, como vimos, Descartes tem o cuidado de se demarcar dos Estóicos. Estes são críticos relativamente às paixões que consideram nocivas e que, como tal, combatem frontalmente. Ora a visão cartesiana é optimista. Não só porque quem vive intensamente as paixões é capaz de proporcionalmente gozar melhor as doçuras da vida ${ }^{61}$ mas também porque é sempre possível um controlo passional.

Tal como o autor francês, Espinosa coloca-se deliberadamente no registo terapêutico, utilizando uma linguagem médica-affectuum remedia. Mas esta aparente aproximação é imediatamente desautorizada pelas duras críticas que Espinosa tece a Descartes, recusando as suas explicações tanto no plano fisiológico, como no que respeita à antropologia, ou no terreno epistemológico. O texto do prefácio é duro - o inter-accionismo concretizado no recurso à glândula pineal é ridicularizado e Espinosa espanta-se que o defensor das ideias claras e distintas apresente neste domínio uma "hipótese mais oculta do que toda a qualidade oculta" ${ }^{2}$.

Eșta perspectiva severa vem de trás, remonta ao escólio da proposição II do livro III da Ética, onde Espinosa apresenta uma verdadeira declaração de princípios, postulando um monismo antropológico. Embora não referido explicitamente, Descartes é o alvo visado. É a ignorância que impede os homens de determinar o que pode um corpo. São os preconceitos que fazem a alma responsável por muitas das actuações corpóreas, pressupondo que estas ocorrem "a sola mentis voluntate". O desconhe-

58 Et. V, Praef., G. II, p. 279.

59 "Transeo tandem ad alteram Ethices partem...".

G. II, p. 227.

60 Carta de Descartes a Chanut, 15 de Junho de 1646, AT, IV, p. 442.

Espinosa, Et. V, prop. XXIX, dem.

61 Les Passions de l'Ame, art. ${ }^{\circ} 212$.

62 "(...) Hypothesin sumat omni occulta qualitate occultiorum" Et. V, Praef, G. II, p. 279. 
cimento dos poderes do corpo e daquilo que ele pode fazer leva os homens a atribuir à alma a responsabilidade de certos desempenhos.

A crítica é forte e parece-nos a uma primeira leitura que Espinosa tem como alvo o homem comum. Mas o passo que se segue não deixa margem para dúvidas. Ao contestar aqueles que defendem o dualismo e o interaccionismo, ficamos cientes de que o visado é Descartes. E, curiosamente, o problema levantado retoma algumas das interrogações da Princesa Elisabeth da Boémia ${ }^{63}$ : não é possível determinar nem a razão pela qual a alma move o corpo, nem os meios de que se serve, nem os graus de movimento que lhe imprime, nem a velocidade desse movimento. Aquilo que perturbou Elisabeth também perturba Espinosa.

Na base destas divergências está um desentendimento quanto ao papel da paixão. Descartes define paixão e explica-a inequivocamente nos artigos 27, 28 e 29 das Paixões da Alma. Por eles ficamos cientes de que os pensamentos designados por paixões têm uma tripla conotação: representativa, sensorial e emotiva. Já no artigo 17 a paixão é apresentada como um tipo de pensamento próprio da alma, da qual esta não tem responsabilidade visto ser provocada por causas extrínsecas. Num sentido lato, tudo o que se passa num sujeito do qual ele não é causa, tudo o que o torna passivo e que ele não domina, é paixão. Mesmo quando se trata de percepções intelectuais, falamos de passividade pois percepcionamos ideias que não criámos. Só os actos voluntários ("volontés") são activos.

As paixões cartesianas incluem duas classes: as que dependem exclusivamente da alma e nada mais são do que a consciência dos estados desta, e as que têm o corpo como causa, sejam elas dependentes dos corpos externos ou do corpo próprio ${ }^{64}$. É nestas últimas que nos centramos, até porque é para elas que o filósofo, stricto sensu, reserva o termo paixão ${ }^{65}$. São estas paixões que ele pretende controlar de modo a alcançarmos uma beata vita. Não se trata de um combate travado frontalmente contra o nosso corpo mas sim de uma acção indirecta sobre ele pela interferência da vontade, que age sobre os afectos através de representações.

Para Espinosa a paixão é uma das manifestações do afecto e por afecto ele entende tanto a afecção do corpo como a ideia dessa afecção. O afecto é algo de transitivo, susceptivel de aumentar ou diminuir a nossa potência. Se somos causa adequada dessas afecções situamo-nos no registo da acção. Caso contrário confinamo-nos à paixão ${ }^{66}$.

Na perspectiva de Descartes o afecto é sempre passivo.

Para disținguir acção e paixão Espinosa usa um triplo critério: ético, gnosiológico e ontológico. É sobretudo a partir deste último que as divergências com Descartes são mais fundas. Senão vejamos.

Do ponto de vista ético a paixão é dependência enquanto a acção é autonomia. É absurdo lutar contra as paixões consoante nos é afirmado no prefácio do Livro V. Os dois filósofos estão de acordo quanto à importância atribuída ao conhecimento das paixões, como condição essencial para o tratamento das mesmas. A diferença surge no passo que se segue a esse conhecimento. Descartes tem como objectivo a anulação das paixões, de modo a assegurar uma vida estável. Para ele as paixões são sempre disruptivas. $\mathrm{O}$ ideal seria não as ter mas já que são inevitáveis há que as combater de um modo eficaz. A perspectiva de Espinosa é de superação, o que significa conviver com as paixões e geri-las da melhor maneira. A passagem da paixão à acção não implica um combate directo à primeira - uma tese que parece próxima das posições cartesianas.

63 Vj. Cartas de Elisabeth a Descartes em 6/16 de Maio, 10/20 de Junho e 1 de Julho de 1643.

64 O primeiro caso é explicitado na Carta a Elisabeth de 21 de Maio de 1643. A mesma tese é sustentada em Les Passions de l' Âme, II, art. LI. Para ilustrar o segundo, veja-se da mesma obra, II, art. LXXIX e a Carta a Chanut de 1 de Fevereiro de 1647, AT, IV, p. 609.

Tal facto levará Jean-Marie Beyssade a falar de uma dupla teoria dos afectos em Descartes.

Vj. "De l'émotion intérieure chez Descartes à l'affect actif spinoziste" in Spinoza Issues and Directions, pp. 175 e segs.

65 Passions de l'Ame, I, art. XXV, AT, XI, p. 347.

66 Et. III, def. III. 
Só que para o autor da Ética o ponto de partida para o governo das paixões é o "conatus", enquanto que nas Paixões da Alma o combate se orienta pela vontade de cada um. Descartes defende a razão como faculdade autónoma, com o poder de dialogar com a vontade e até de se incompatibilizar com ela. Espinosa combate uma teoria das faculdades - desejo, vontade e razão são meras manifestações do "conatus". Enquanto princípio de movimento, é ele que nos faz agir. É o desejo que conduz à moral. Não há valores maiores do que os que nos levam a perseverar no ser. O bem e o mal são posteriores ao desejo e derivam dele ${ }^{67}$. Assim, a liberdade cartesiana define-se pelo poder da yontade, enquanto a liberdade espinosana implica a vivência total da essência própria. É aprendendo a ser, e não pelo recurso a uma qualquer força exterior, que dominamos as nossas paixões ${ }^{68}$. Trata-se de uma libertação, da conquista de um estado que paulatinamente se vai adquirindo e que profundamente nos transforma.

A utilização do conceito de "conatus" para definir a natureza humana aproximando-a de todos os outros modos, é um passo essencial na demarcação com.Descartes, substituindo uma visão mecanicista por uma perspectiva dinâmica. O "conatus" enquanto força bipolar passiva e activa, sempre susceptível de correcção e de melhoramento, anula qualquer perspectiva inter-activa entre corpo e alma, tornando inútil o recurso à glândula pineal. A razão e a vida cruzam-se e identificam-se na essência dinâmica de cada homem - o "conatus". Este é um foco particular da "potentia" divina na qual se inscreve a possibilidade de realização individual. E é esse esforço de preseverança e de resistência, de afirmação e de apropriação que permite a cada homem crescer.

Explicada a partir da sua vertente gnosiológica, a paixão em Espinosa corresponde a uma ideia confusa, a acção a uma ideia clara. Ao tornar claros e distintos os nossos conceitos tornamo-nos activos ${ }^{69}$. A paixão surge como indicador gnosiológico pois há uma catarse passional que acompanha os diferentes graus de conhecimento e que se reveste de diferentes formas mas que nunca se anula. É a maximização do desejo que conduz ao conhecer. A razão recebe o seu ritmo do desejo, copia as estratégias dos afectos. Há que manusear as paixões de modo a pô-las ao serviço da razão. O esforço supremo ("summus mentis conatus") é igual à suma virtude e consiste em alcançar o conhecimento do terceiro género ${ }^{70}$.

Já no livro IV, a partir da proposição XL, o filósofo se debruçara sobre os afectos, distinguindo os que são prejudiciais a uma conduta racional dos que a favorecem. O sábio não está isento de paixões, apenas as sabe gerir de um modo inteligente. Ao remetê-las para a ideia de Deus, como nos é proposto no livro $V^{71}$, ele consegue eliminar afectos negativos substituindo-os por outros mais fortes. A tese, defendida no livro IV, de que o conhecimento só por si não anula as paixões e apenas o consegue se funcionar como um afecto ${ }^{72}$, é recuperada no livro V, concretizando-se na ideia de Deus, que agora surge como o mais poderoso dos afectos.

Também Descartes admite que o conhecimento - e nomeadamente o conhecimento racional - é um auxiliar importante no combate às paixões. Mas se para ambos o conhecimento é libertador, aquilo que ele nos revela é significativamente diferente para cada um dos filósofos. Em Espinosa o conhecimento mostra-nos a estrutura necessária do Universo, na qual a contingência é apenas fruto da ignorância. As coisas são absolutamente determinadas e descobri-lo é perceber também a inevitabilidade das

67 Et. III, prop. IX, schol.

68 A autonomia da vontade é constantemente recusada na Ética. Veja-se particularmente Et. II, prop. XLVIII.

69 Et. V, prop. III.

70 Et. V, prop. XXV.

71 "Mens efficere potest, ut omnes Corporis affectiones, seu rerum imagines ad Dei ideam referantur" Et.V, prop. XIV, G. II, p. 209.

72 "Vera boni et mali cognitio, quatenus vera, nullum affectum coercere potest, sed tantum ut affectus consideratur" Et. IV, prop. XIV, G. II, p. 219. 
nossas paixões ${ }^{73}$. A alma é um "autómato espiritual"74 e a "ordo rerum" tem o seu reverso na "ordo idearum". As mesmas leis regem corpos e mentes.

Nunca Descartes aceitaria esta integração numa cadeia de causas e efeitos, nem uma concepção de homem como ser determinado. Para ele, o mundo da matéria é sujeito a leis mecânicas enquanto o do pensamento é totalmente livre. Se há divergências nos planos ético e gnosiológico dos afectos, o divórcio é total no que respeita à radicação ontológica dos mesmos. Para o autor da Ética os afectos prendem-se com a nossa integração no mundo. Estamos no mundo e por isso somos afectados pelos outros corpos e estabelecemos relações com eles. Se nos limitamos a sofrer passivamente a actuação dos objectos, sem a compreender, somos causa parcial do que nos acontece e tornamo-nos passivos. Se procurarmos ser causa adequada do que nos afecta, compreendendo-o, então somos activos.

Tal como há "genera cognitionis", também há, embora não explicitamente demonstrados, "genera vitae". A paixão é indicativa do nosso estar no mundo e da nossa capacidade de relacionamento, pressupõe uma relação extrínseca com os outros modos. Há que a transformar em actividade. Tal facto dá-se quando nos conseguimos libertar das causas exteriores e recuperamos todos os elos que nos ligam ao Todo. O desejo que nos habita e nos mantém vivos, orienta-nos para determinados objectos. A Ética oferece-nos estratégias de racionalização do desejo. Importa-nos atingir o objecto com o qual estabeleçamos um vínculo profundo e duradouro. É a excelência do objecto ao qual nos unimos que determina a diferença entre paixão e acção. Quanto mais excelente, quanto mais total e não particular for o objecto a que nos unimos, mais activos seremos. O objectivo último é a união com toda a Natureza, de tal modo forte que domina todas as nossas paixões.

Para Espinosa a explicação última das paixões é ontológica e não biológica, psíquica ou mesmo moral. A ontologia espinosana procura a todo o custo estabelecer os elos que ligam os modos entre si e que simultaneamente os integram no Todo. É este ideal de continuidade que o leva a uma visão solidária de toda a Natureza e que o faz escrever a Oldenburg que se uma parte desta se anulasse tudo se aniquilaria ${ }^{75}$. Ser indivíduo é pertencer a uma rede de indivíduos. É relacionar-se com outros indivíduos com os quais se constrói algo em comum. Seja na política, na filosofia, na beatitude, há um sentido comunitário profundo. O melhor dos bens é alcançar a união com a Natureza e fazer com que muitos indivíduos gozem de tal beatitude ${ }^{76}$. Não somos micro-cosmos, nem substâncias, nem totalidades autónomas. Se para Decartes, o conhecimento que cada indivíduo tem de si mesmo lhe pode trazer felicidade, ajudando-o a conhecer e a dominar as suas paixões, para Espinosa há que passar a um nivel mais alto, em que a individualidade e os conflitos se transformam em solidariedade e comunidade.

Logo no início do livro $V^{77}$ é-nos afirmado que a libertação de uma causa exterior e a junção de um pensamento a outros pensamentos leva à destruição das paixões de amor e de ódio. A paixão separa-nos dos outros e do Todo e o conflito tem a ver com a perda de unidade. A originalidade de Espinosa está em reconhecer que um afecto só pode ter destruído por um afecto maior ${ }^{78}$ e como tal, que a estabilidade só será adquirida quando nos unirmos com o objecto mais poderoso de todos - Deus sive Natura. Padecemos enquanto somos parte da Natureza. O desejo leva-nos a Deus e simultaneamente devolve-nos o lugar que ocupamos no Todo. Percebemos então que somos afecções da divindade e que estabelecemos com os outros modos um certo número de relações que não interessa contrariar mas sim compreender.

É esta dimensão cósmica e salvífica, omissa em Descartes, que nos permite dizer que, neste caso, o discípulo visou mais longe do que o mestre.

73 Et. V, prop. VI.

74 “(...) quasi aliquod automa spirituale”. TIE, § 85, G. II, p. 32.

75 Ep. IV A Oldenburg, G. IV, p. 14.

76 TIE, §§ XIII e XIV e Et.V, prop. XX.

77 Et. V, prop. II.

78 Et. V, prop. VII. 